\title{
Design and Aural Analysis of Signal Processing Using Time Delay
}

\author{
Designe Análise Aural do Processo de sinal usando Time Delay
}

\author{
Mauricio Perez \\ Regis Alves Rossi Faria \\ Rodolfo Coelho de Souza \\ Universidade de São Paulo
}

\begin{abstract}
This paper presents the design in PureData of some audio signals processes in real time like delay, echo, reverb, chorus, flanger e phaser. It also applies techniques of Aural Analysis, which intends to solve problems of intrinsic sound perception. We analyze the technical characteristics of each process and the psychoacoustic effects produced by them in human perception and audio applications. The approach for these processes is based mostly on Roads (1996), Berardino and Puckette (2006). We look for a better understanding of how some sound processes based on delay lines, such as simple delay, reverb and echo, affect the frequency spectrum of the processed sound during the time flow. Besides that, we identified other processes that also affect the spectrum, such as chorus, flanger e phaser, which nevertheless many times are not classified as resulting from time processes but as general effects. A deeper comprehension of the consequences of sound processes based on delay lines favors not only the awareness for the identification of the involved phenomena but also the technical choice of which process to use. This knowledge also helps the decision-making in professional audio applications such as the choice and positioning of microphones for audio recording in different acoustic spaces. This skill also benefits sound edition and mixing, besides music composition that employs sound effects in pre-processed or real time.
\end{abstract}

Keywords: Aural analysis; Audio signal processes; Delay line; Sound effects; Electroacoustic music

Resumo: Este artigo apresenta alguns métodos para se projetar determinados processos de sinal de áudio em tempo real, tais como delay, echo, reverb, chorus, flanger e phaser. Aplica também técnicas de Análise Aural, que buscam resolver problemas da percepção intrínseca do som. Analisamos as características técnicas de cada processo e os efeitos psicoacústicos produzidos por eles na percepção humana e nas aplicações de áudio. A abordagem desses processos foi baseada preponderantemente em Roads (1996), Berardino e Puckette (2006). Buscamos um entendimento aprofundado de como alguns processos baseados em linhas de atraso, como atraso simples, reverberação e eco, afetam o espectro de frequências do som processado ao longo do fluxo temporal. Além disso, identificamos outros processos que também afetam o espectro, tais como chorus, flanger e phaser, os quais, no entanto, não são

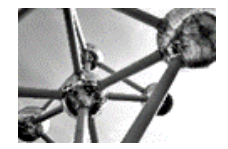

Revista da Associação Brasileira de Teoria e Análise Musical

Journal of the Brazilian Society for Music Theory and Analysis

@ TeMA 2019- ISSN 2525-5541 
classificados como resultantes de processos temporais, mas como efeitos gerais. Uma compreensão mais profunda das consequências dos processos sonoros baseados em linhas de atraso favorece não somente a consciência da identificação dos fenômenos envolvidos, mas também a escolha técnica de qual processo usar. Este conhecimento também auxilia o processo decisório na vida profissional em aplicações de áudio, tais como a seleção e o posicionamento de microfones em gravações de áudio em diferentes espaços acústicos. Esta habilidade também beneficia a competência em edição e mixagem sonora, além de ser útil para a composição musical que empregue efeitos sonoros em tempo real ou pré-processado.

Palavras-chave: Análise aural; Processamento de sinais de áudio; Linhas de atraso; Efeitos sonoros; Música eletroacústica

\section{Introduction}

The technique of time delay is simple and versatile. It is often used in audio signal processing for fixing a large array of technical problems, like problems of sound diffusion in concert halls, or it is applied to audio effects that expand the capabilities of acoustic instruments, modifying and creating new timbres for the purpose of music composition.

In this paper, we chose to explore this second trend. Notice that, from the psychoacoustic standpoint, effects based of time delay are related to how the human hearing apparatus receives and interprets the delayed signals. We may understand them as repetitions, some feature of the acoustic space or as the timbre that results from transformations in the spectral dominium.

From the beginning, it is important to remark that time delays are not germane to digital means or to signal processing techniques. On the contrary, the techniques of signal processing, analogic or digital, strive to emulate effects that occur in nature, in many forms, according to properties of an infinite variety of listening environments. Depending on how much time a sound takes to reach each of our two ears, we may have a different perception of any specific sound. Besides that, sound reflections on certain surfaces may multiply or change parameters that we related to properties of the sound sources, thus creating sets of different delays as the result of absorption and reflection on these surfaces.

The first uses in music of sound effects based on time delay, goes back to the 1940's. They were delay effects and short echoes that used tape loops in magnetic sound recorders. This procedure was called tape delays. The amount of the time delay was ruled by the distance between the reading and recording heads of the devices. This loop arrangement might generate an echo effect that 
could be one or many repetitions of the signal to be added to the original signal on another recording device. Until de decade of 1970s this was the basic configuration for an echo system. Based on it, the industry perfected the system to allow the generation of the effect using only one tape and multiple reading/recording heads besides the control of the tape reading speed.

After the 1970s, the development of new systems of time delay were possible due to the miniaturization of electronic components. The most common used analogic delay lines were based on the operation of a set of capacitors installed on integrated circuits. This operation consisted on the exchange of electrical charges between the capacitors to generate a constant cycle and consequently a time device. This device was called the bucket brigade device because its mechanism, based on the principle of electric capacitance, can be compared to a line of people transferring buckets of water to the neighbor during a certain period.

After the 1980s new kinds of systems based on integrated logic circuits allowed the discrete manipulation of audio signals. These new devices were able to transform the analogic audio signal into the digital domain. Then, the audio signal could be treated as numerical data that could be manipulated in ways that avoided the limitations of reproduction and time control inherent to analogical processes, which depend on constant flows of reproduction and processing. Figure 1 displays the basic functioning scheme of a delay line, which can be implemented analogically or digitally.

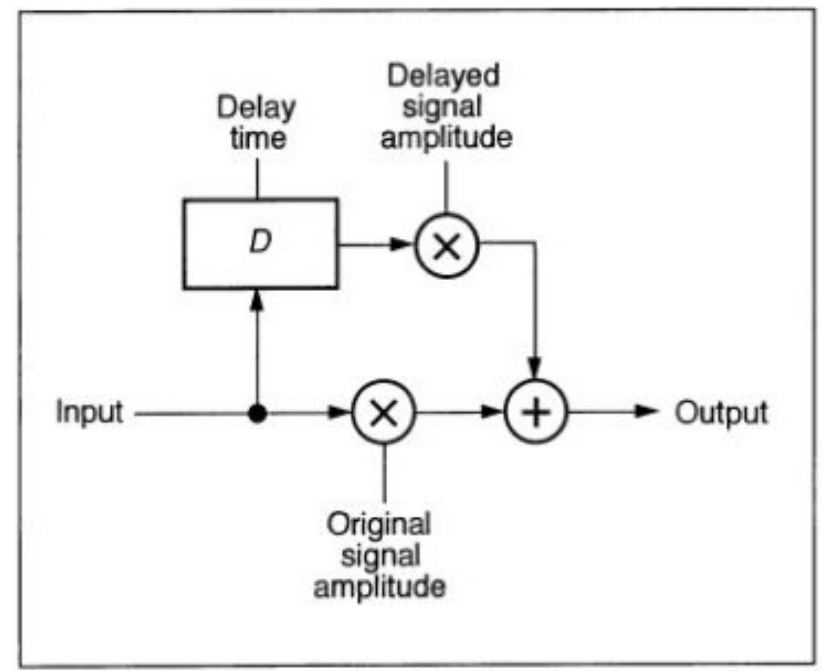

Figure 1: Circuit of a delay line (after Roads 1996, p. 432) 
Because only the digital domain concerns us here, time delay effects can be implemented using a function called digital delay line. Figure 2 displays its workings that, according to Roads (1996, p. 433) consists in "a data structure called a circular queue" in which a list of memory locations, disposed sequentially in the computer's memory, stores the numerical representation of audio samples.
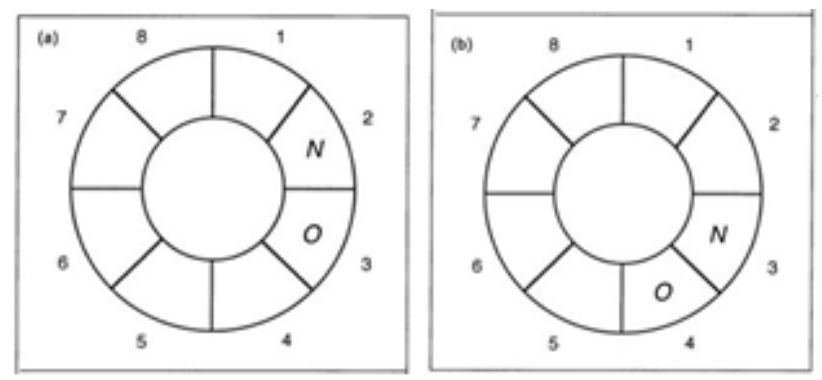

Figure 2: Operation of a circular queue to implement a delay line (after Roads 1996, p. 433)

The program that executes the delay line reads the old sample $(\mathrm{O})$ and replaces it with a new incoming sample $(\mathrm{N})$. Then the pointer that reads and writes moves to the next position containing an old sample and recursively does the same procedure until reaching the end of the line. When the pointer reaches the final position (8), it moves back to the first position (1). In the language of signal processing, we say that this pointer executes a tap. This way it is possible to have more than one reading pointer to the same buffer and therefore create $a$ multitap delay line.

\section{Implementation of delay lines in PureData}

The design of delay lines using the software PureData (Pd) (Puckette, 2006) can be implemented using the objects [delwrite ] and [delread ]. The first object is responsible for creating the circular buffer, as displayed above, containing the audio samples, which the second object reads and reproduces. Both objects receive two arguments on the right side. The first argument of [delwrite ] is the location that stores the buffer (in this instance called "delay") and the second argument stores the time of the buffer (in this instance 200 milliseconds). 
The arguments of [delread ] are respectively the sample that will be read (delay) and how large is the delay time (1000 ms). For a multitap type of delay line it is enough to create other delay readers that can hold different delay times.

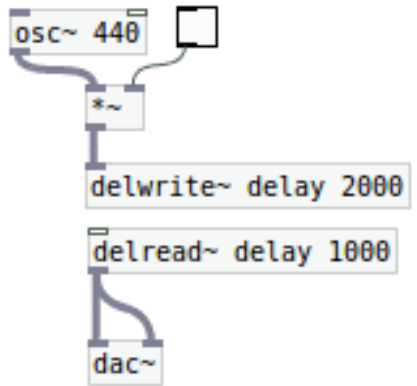

Figure 3: Design of a delay line in PureData

Roads (1996) remind us about the difference between two types of delay lines: those that use a fixed time of delay and those that use a variable time of delay. The difference is that unities of fixed delay time do not change their time of delay while they process the sound. However, in a unity of variable time of delay, this time can be changed at any moment by varying the reading pointers at each sample period. These two types of delay are also inherent to specific temporal processes. The first case, of unities of fixed time of delay, we can found in the most common processes of delay as delay proper, echo and reverb when generated by delay lines. The second case is used in processes like chorus, flanger and phaser. Therefore, we will start demonstrating the implementation of patches that use lines of fixed delay time, followed by those that use variable delay lines.

\section{Effects with fixed delay lines: delay, echo and reverb}

According to Roads (1996, p. 435) fixed delay lines can be arranged in three categories with specific interval times which correspond to three categories of perceptual effects, related to the human hearing, that different interval times can generate. These three interval times are: short interval times (up to $10 \mathrm{~ms}$ ), medium interval times (from $10 \mathrm{~ms}$ to $50 \mathrm{~ms}$ ) and large interval times (larger than $50 \mathrm{~ms}$ ). Short interval times are perceived mainly in the frequency domain as artifacts added to the original signal. When a delay line operates between 0,1 and $10 \mathrm{~ms}$, it generates a comb filter effect that can add frequencies to the original signal. Medium interval times are perceived as an ambience created around the original sound. This means that the signal is amplified by the sum of the original 
signal with other signals generated by the delay line. Therefore, the loudness of the original signal seems to increase. Finally, delay lines with large delay times generate a perception of sequential repetitions of the original signal. They correspond to larger spaces with more and distinct reflections.

The implementation of a simple delay effect was already demonstrated, inasmuch it corresponds exactly to the creation of a simple delay line. We will deal now with the design of many delay lines to create the effects of echo and reverb. These effects can be created with an algorithm that generates a mechanism of feedback of the original signal into the unity of delay processing. The larger the feedback gain, the larger will be the number of generated delays. Nevertheless, the result will always be a mixture of the original signal with the processed signal.

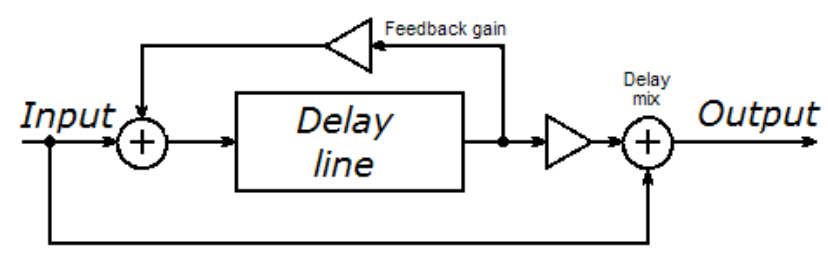

Figure 4: Algorithm of a delay with feedback. (from: https://www.hobbyhour.com/guitar/delay_effects.php)

To implement in PureData a delay with feedback we use again the objects [delwrite ] and [delread]. However, this time the reading of the pointer will be reintroduced into the processing chain. Besides that, we must add a gain control to the feedback, which, as we said, also controls the number of repetitions. We must emphasize that this gain control must be smaller than the maximum possible amplitude, which, in PureData is 1.0, otherwise the repeated signal will have the same amplitude of the incoming signal what will generate an endless loop repetition and amplitude distortion.

This way, with specific combinations between delay times and feedback gains, we may implement different time processes based on fixed delay lines, as those described above, and as shown on Table 1. 
MUSICA THEORICA Revista da Associação Brasileira de Teoria e Análise Musical 2019,

v. 4, n. 2, p. 229-246 - Journal of the Brazilian Society for Music

Theory and Analysis @ TeMA 2019 - ISSN 2525-5541

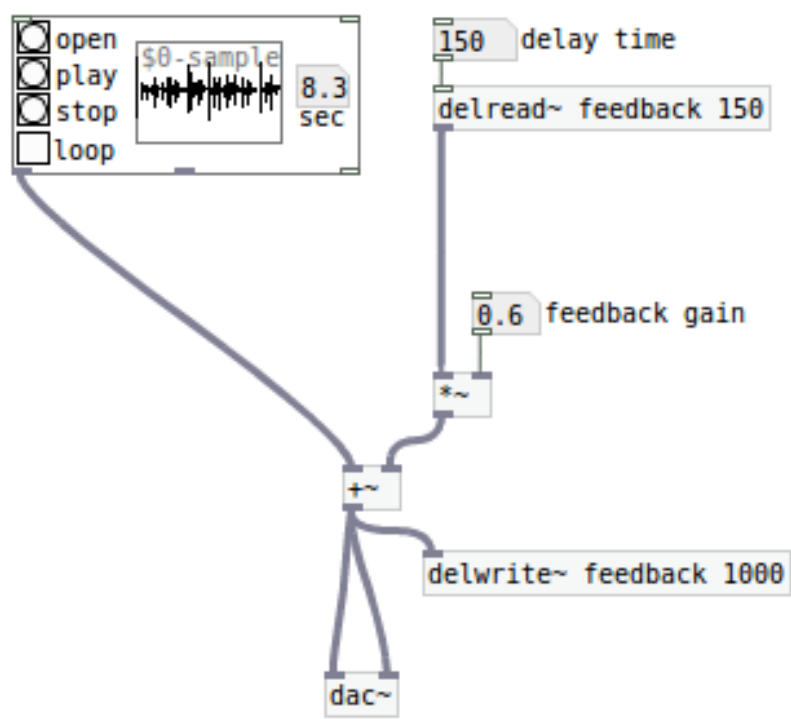

Figure 5: A model of delay with feedback in Pd

\begin{tabular}{|l|c|c|}
\hline & delay time & feedback gain \\
\hline comb filter & $1-10 \mathrm{~ms}$ & 0,9 \\
\hline loudness boost & $10-50 \mathrm{~ms}$ & $0,5-0,3$ \\
\hline short echo & $50 \mathrm{~ms}$ & 0,7 \\
\hline large echo & $100 \mathrm{~ms}$ & $0,7-0,95$ \\
\hline short reverb & $100 \mathrm{~ms}$ & 0,3 \\
\hline large reverb & $150 \mathrm{~ms}$ & 0,5 \\
\hline
\end{tabular}

Table 1: Effects based on delay time and feedback gain

As we may identify on Table 1, the main difference between the effects echo and reverb lays on the delay time and the number of delays. Echoes are characterized by a larger time distance between the original signal and the delayed signal, what allows the human ear to listen and identify the repetition as a signal independent of any other signal. For the reverb, however, the spacing is shorter, emulating the fast reflections of smaller acoustic spaces. On the other hand, the quantity of delays generated by the feedback influences the number of echoes that we listen to, and the intensity and the depth of the reverberation. Despite that, these two effects are not entirely incompatible as we may identify traces of one in the other and vice-versa. The sonograms of Figures $6 \mathrm{a}$ to $6 \mathrm{~g}$, produced with the software Spek with audio samples in '.wav' format, mono/44100/32 bits, represent the spectral analysis of different processes applied to a sound sample according to the parameters of Table 1. They allow us to visualize the differences between these processes. 
First, in relation to the boost effect of the original sound, we may notice how the $-60 \mathrm{~dB}$ region increases in relation to the original sound. This is caused by the summation of spectral content of the sound on top of the original sound, enhancing amplitudes of frequencies that already exist in a certain instant. This kind of densification can also be identified in other effects. In relation to the comb filter effect, we may notice in the spectrogram that some high frequencies appear and the intervals are fulfilled although in a rarefied way. This happens because the original signal and the processed signal become, quite fast, out of phase, generating constructive and destructive phase interferences that enhance or cancel the amplitude of the signals. In the effects of $e c h o$ and reverb we can visually identify characteristic elements of each one. We may notice, in the effects of echo, short or large, a visual structure of repetition that indicate different sound events. In the effects of the reverb type, this structure also exists but it is not as much characteristic because the repetition intervals are shorter, what makes more difficult the segmentation, both auditory and visual. What we may identify better is a spectral fulfillment between the repetitions that earlier showed larger time gaps.

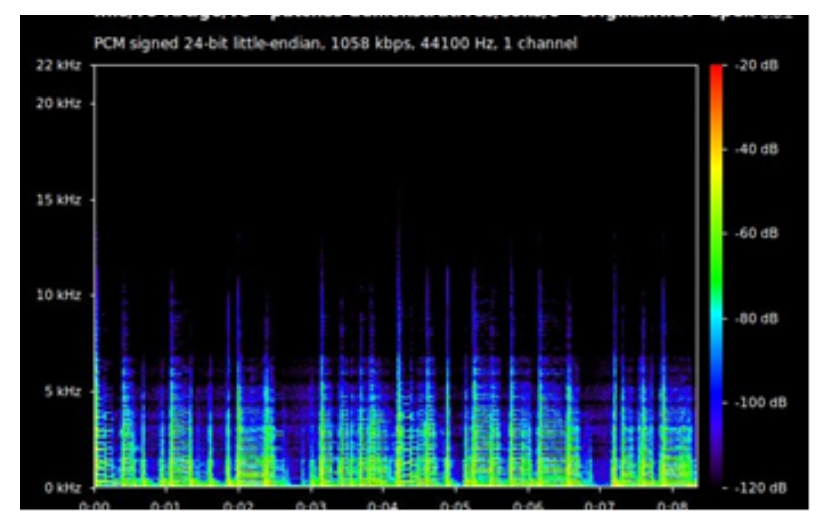

Figure 6a: Original sound 
MUSICA THEORICA Revista da Associação Brasileira de Teoria e Análise Musical 2019, v. 4, n. 2, p. 229-246 - Journal of the Brazilian Society for Music

Theory and Analysis @ TeMA 2019 - ISSN 2525-5541

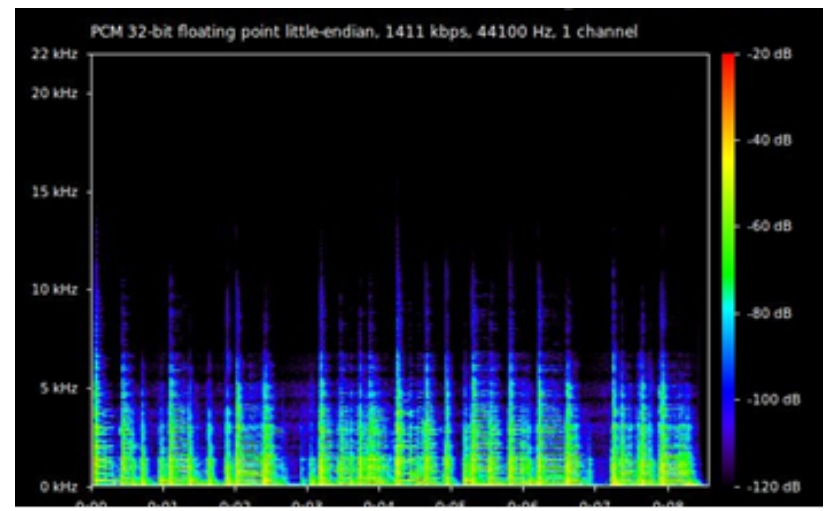

Figure 6b: Loudness boost

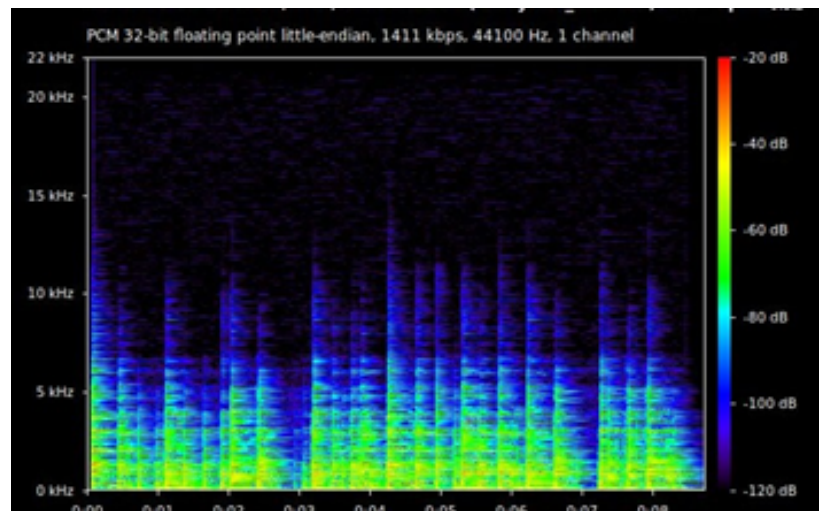

Figure 6c: Comb filter

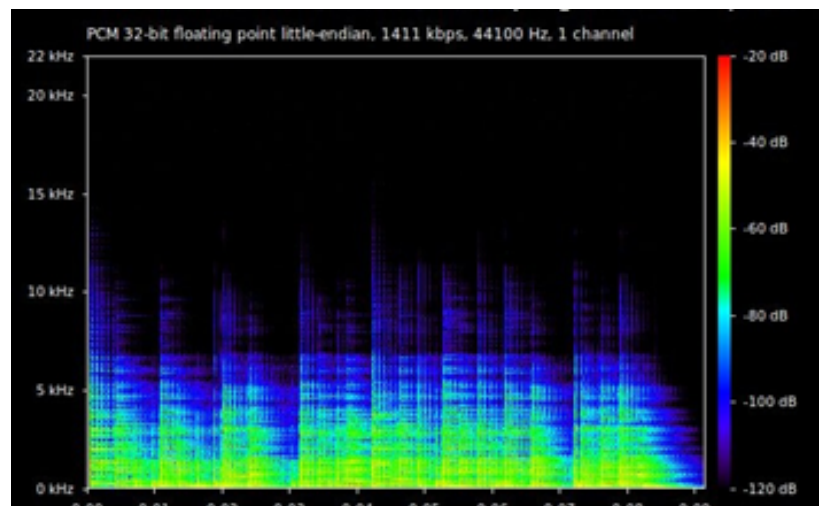

Figure 6d: Short echo 


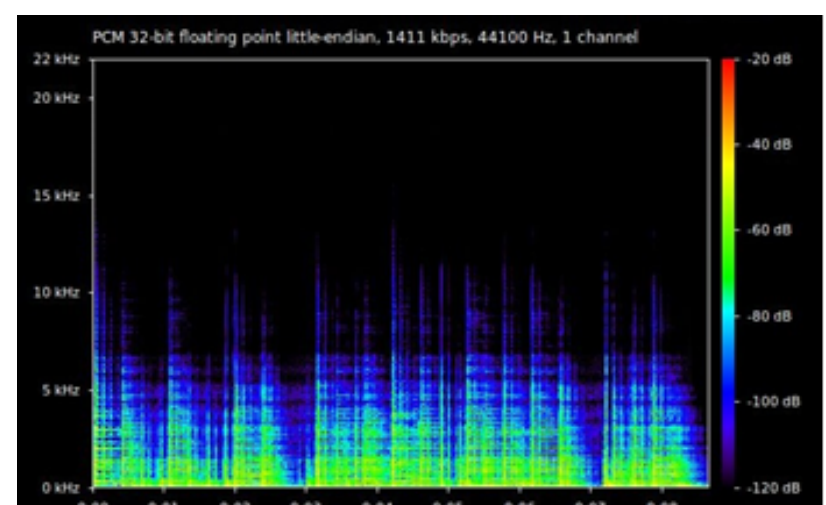

Figure 6e: Short reverb

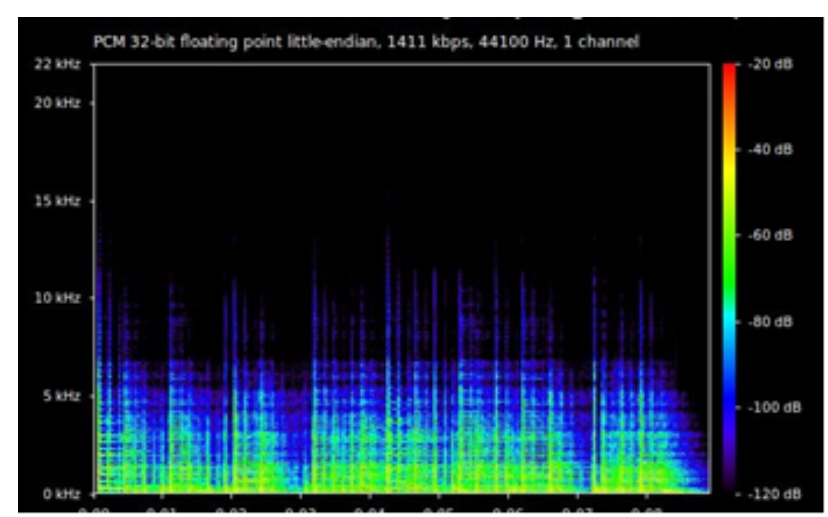

Figure 6f: Large reverb

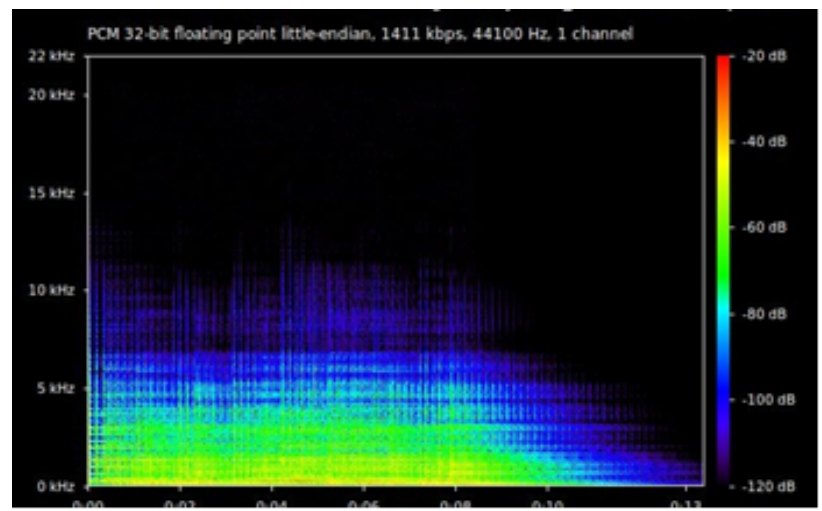

Figure 6g: Large echo

\section{Effects with variable delay lines: chorus, flanger and phaser}

As mentioned above, variable delay lines allow the change of the delay time while the audio signal is processed by the delay unity. This allows the creation of other effects based on delay lines: chorus, flanger and phaser. When we say that a delay line is variable, we are describing a unity of signal processing that has some element that varies constantly. In this case, what varies is the 
MUSICA THEORICA Revista da Associação Brasileira de Teoria e Análise Musical 2019, v. 4, n. 2, p. 229-246 - Journal of the Brazilian Society for Music

duration of the delay time. It can oscillate between a maximum and a minimum value. Analogical or digital devices using a low frequency oscillator (LFO) can implement this kind of effect. The LFO is used to control the delay time. Figure 7 shows a diagram of this process.

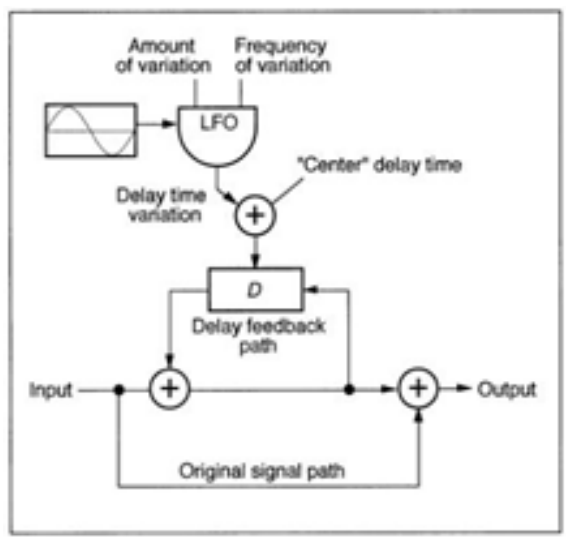

Figure 7: Algorithm of variable delay with feedback (after Roads 1996, p. 438)

Variable delay lines can be implemented in Pure Data using the objects [delwrite ] e [vd ]. The difference between this implementation in relation to the fixed delay lines is that the object [vd ], which is a samples pointer reader, as also is [delread], accepts as input a controlling audio signal. This way, we may use a low frequency oscillator to vary constantly the delay time. In Figure 7, this corresponds to the LFO in the algorithm.

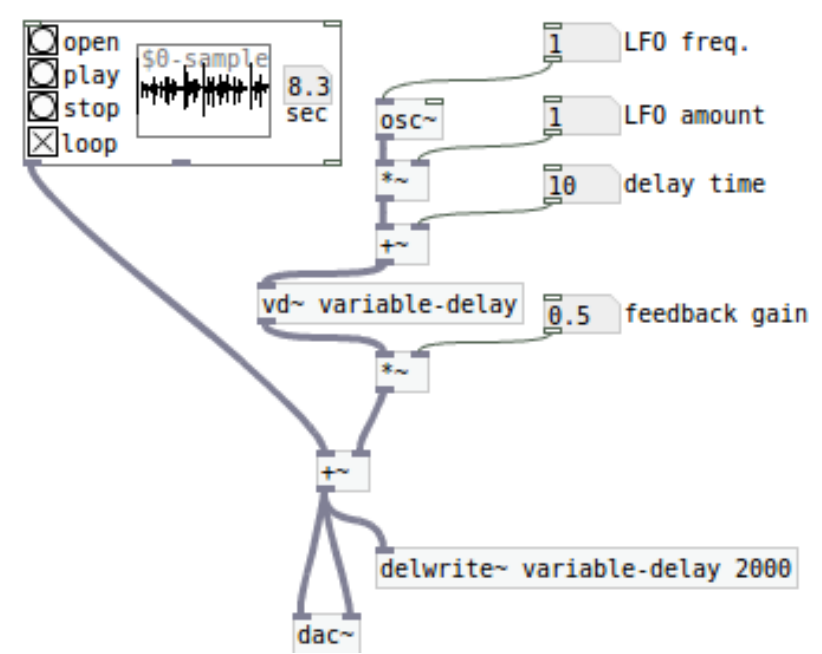

Figure 8: Model of variable delay with feedback

Based on this model of variable delay, we can implement some other effects. These effects have in common that same variable delay unity. However, 
each of them has some special features. One of these features is related to the variation of the delay time. In the case of chorus, for instance, this variation has to be set between 10 and $30 \mathrm{~ms}$. In case of the flanger, the variation can occur between 1 and $20 \mathrm{~ms}$ and in the case of the phaser the LFO may vary from 1 to $10 \mathrm{~ms}$.

As the own name says, the effect called chorus creates the impression that there are many voices besides the original signal. This impression happens due to the phase difference between the delayed signal and the original signal. This is equivalent to the out of phase situation of the voices in a choral. These voices can be out of phase and micro-tuning creates a chorus effect. In the Pure Data, this process can be implemented with the scheme displayed in Figure 9. Notice that, in this case, there is not the presence of feedback. To create an effect with a larger number of voices, we must use more unities of variable delay. Different values for each of them creates a more natural impression of a real chorus effect.

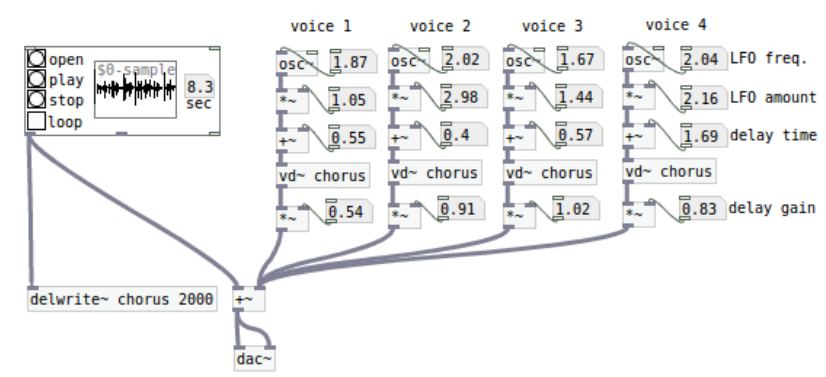

Figure 9: Implementation of chorus effect with 4 voices

According to Roads (1996, p. 437), the flange effect derives from a natural acoustic phenomenon that happens when a large band noise, as a white noise, is mixed with a delayed version of the same sound. This effect can be perceived, for example, in the sound of a airplane turbine passing by with high speed. In 1945, the guitar player Les Paul used two magnetic tape recorders, one of them with variable speed, to simulate this effect. In 1960, the flanger module was implemented in a recording studio using two tape recorders that received the same signal and were mixed in the output. One of these signals was slightly altered by the operator pressing his finger on the flange of the tape reel to slow down the reading. The name of the effect derived from this manual procedure. 
MUSICA THEORICA Revista da Associação Brasileira de Teoria e Análise Musical 2019, v. 4, n. 2, p. 229-246 - Journal of the Brazilian Society for Music Theory and Analysis@ TeMA 2019 - ISSN 2525-5541

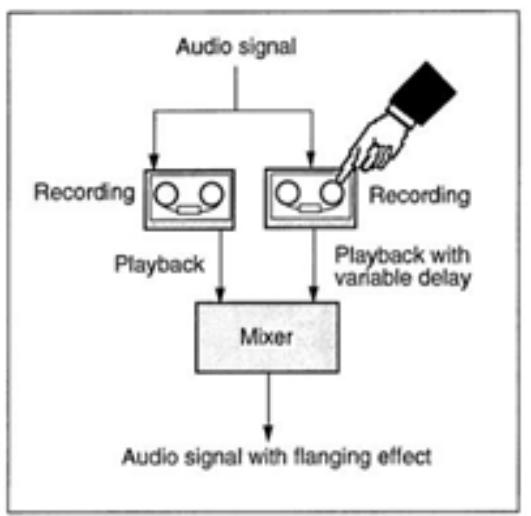

Figure 10: Implementation of an analogical flanger device (after Roads 1996, p. 438)

In $\mathrm{Pd}$, this effect can be implemented with a variable delay line, as shown above. Besides that, to reach an effect closer to the classic effect, we must use lower frequency values for both the LFO and the delay, creating the impression of a slow sweep of the oscillator through the frequency spectrum. The oscillator can also be multiplied to vary its amplitude but only between 0 and 1 (or [- 0.5] and $[+\sim 0.5])$. Notice that, in the case of the flanger, there is a feedback process.

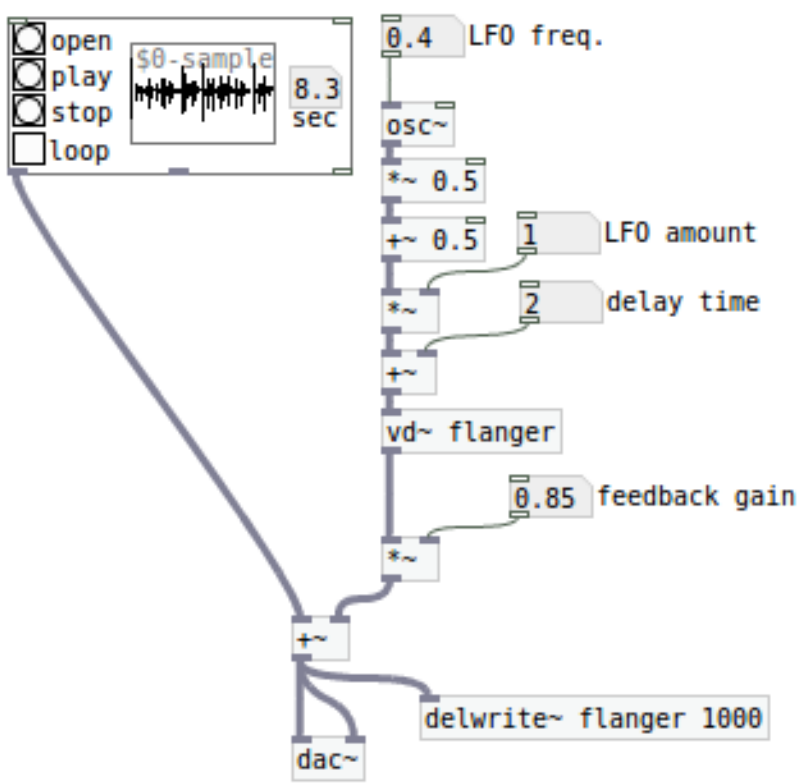

Figure 11: Implementation of a digital flanger

Finally, the phaser effect is quite similar to the flanger effect, however, it does not show the characteristic frequency sweep of the later. Also, differently in the phaser effect, the spectrum generated by the variable delay is sent to a series of all pass filters. These filters, however, do not attenuate any frequency band but modify the initial phase of the signal. The LFO is used to control the amount of 
phase change in each filter. The output of the filters is mixed with the original signal.

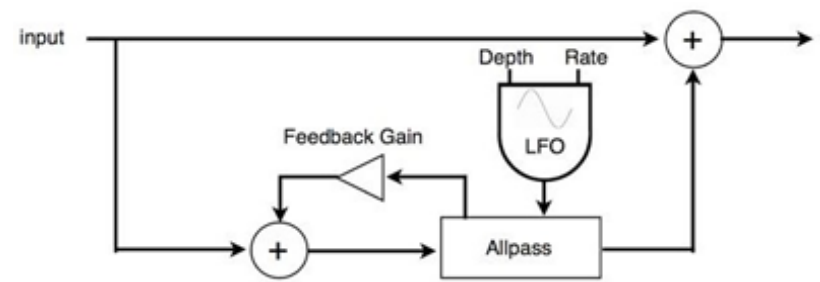

Figure 12: Algorithm of a digital phaser (after Berardino 2017)

The implementation of this algorithm in Pd can be modelled as a variation of the first variable delay model that we presented. We add to it the all pass filter, then we filter the generated signal with the variable delay and add it to the original signal. This time the LFO is controlling the amount of phase changes in the filter. As it can be seen in Figure 13, there is not a series of all pass filters, but the feedback of the delayed signal generates a similar effect because the same signal is filtered many times. Therefore, controlling the feedback, we can control the amount of frequency filtering and the intensity of the phaser effect.

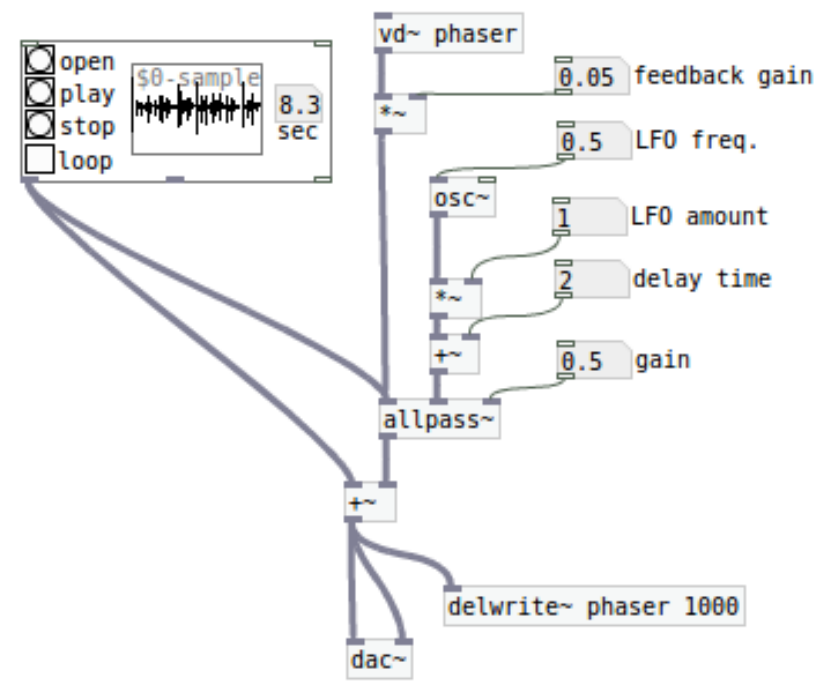

Figure 13: Implementation of the digital phaser algorithm

In the sonograms displayed on Figures 14 a to $14 \mathrm{~d}$, we may visualize mainly looking at the spectral content - the differences produced in the resulting sound signal by each of these different processes of time delay using variable delay lines. A clear distinction between these processes and the processes with fixed delay lines is that their main characteristic concerns changes in the 
MUSICA THEORICA Revista da Associação Brasileira de Teoria e Análise Musical 2019, v. 4, n. 2, p. 229-246 - Journal of the Brazilian Society for Music

temporal/morphological domain of the sound signal, except maybe in the case of the comb filter effect.

In the phaser effect, we may notice a specific undulation feature, with repetitions throughout the process. This feature relates to the behavior of the all pass filters that create spikes and notches due to the reject band characteristic of these filters.

In the flanger effect there is a similar feature, however, in the case of this effect the notches happens due to the difference of phase between the original and the delayed signals, in a periodic way that is the result of the LFO control. Yet in the case of the flanger, we may notice also that the high frequencies are placed at symmetrical time intervals due to the frequency sweep of the LFO.

Last, in the chorus effect, we may notice a large spectral densification produced by the multiplication of the original sound in other voices. However, in this case, we cannot easily identify the vibrato effect usually generated by the LFOs.

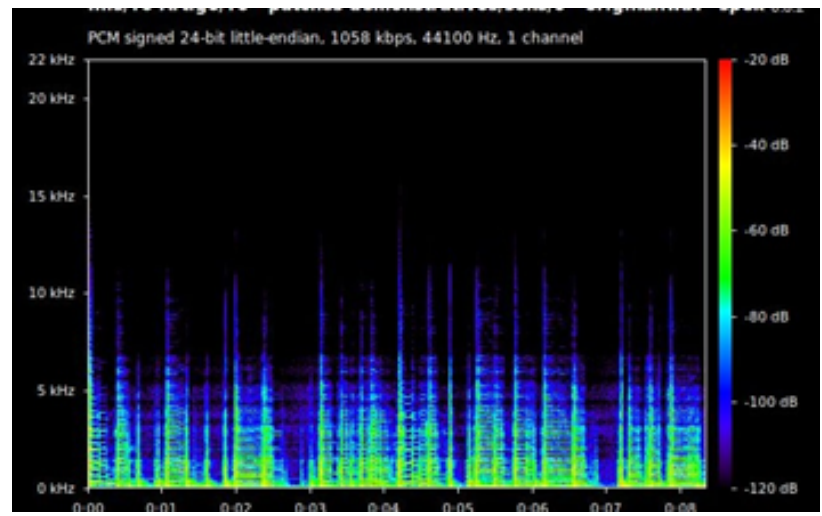

Figure 14a: Original sound

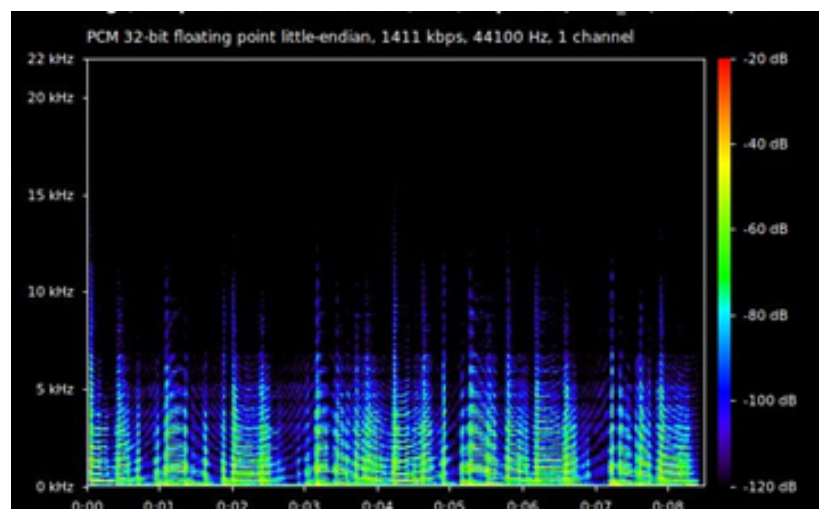

Figure 14b: Phaser 


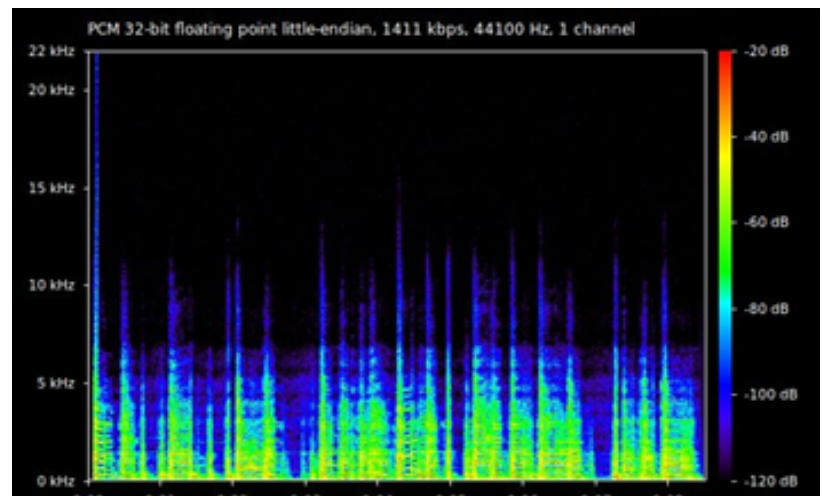

Figure 14c: Chorus

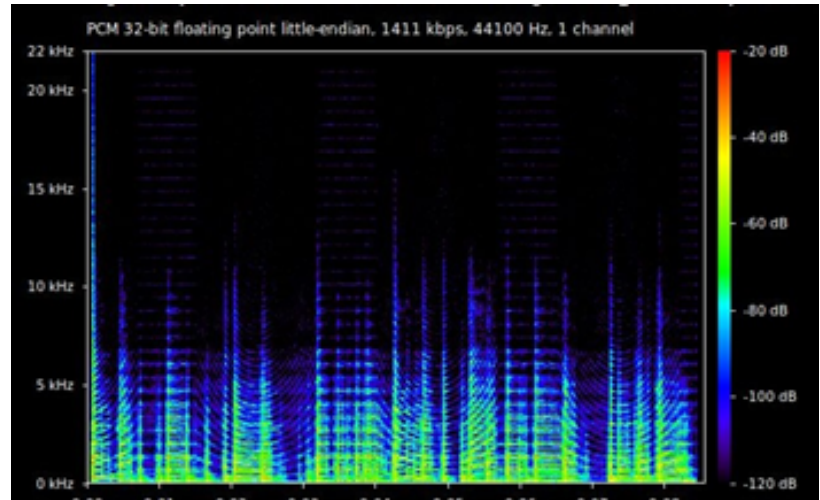

Figure 14d: Flanger

\section{Conclusions}

The understanding of the different types of signal processing, generated by fixed or variable delay lines, enhances the decision-making process in situations when we face professional audio problems from technical or aesthetical points of view. This can happen in a simple sound recording session, in an audio mixing station or during the composition of electroacoustic music that employs pre-processed or real time sound effects.

Being able to differentiate between the results of processes such as comb filter, phaser and chorus can be quite useful. These effects result from delays that generate time displacement between their repetitions. This causes changes in the harmonic spectrum.

The awareness of time elements can be useful in many situations, for instance in room reverberation, identification of obstacles in sound trajectory or recognizing phase cancelation in a recorded sound. 
Therefore, in these cases, acknowledging the time prevalence in the situation can help the decision making to avoid attention only to the frequency domain, what can lead the sound engineer to use, for instance, a frequency filter to change the spectrum involuntarily. Indeed, we may create desirable effects with other strategies, like setting a short time displacement between similar tracks, as we use to do in voice or instrumental unison doubling. The result is an enlarged sound ambience and reinforcement of harmonic partials produced by constructive interference.

Similarly, we must be aware of changes in the spectrum domain generated by basic effects as reverbs and simple delays, as generated by delay lines, because they may be desirable or not. The superposition of repeated sound materials usually produces reinforcement of certain frequencies, generating an effect aesthetically desirable or just distortion. Our experience tells that this situation can happen when recording in a room with large reverberation. For the performer, the sound seems nice but the signal for microphone caption can already be saturated at the source.

These experiments also demonstrate that the human perception of delays shows a double standard. Delays larger than $50 \mathrm{~ms}$ are interpreted by our brain as isolated repetitions while shorter delays just change certain frequency components of a single sound event.

What has been presented in this paper was a reasoning for the implementation of many types of signal processing with time delays. The kind of reasoning used was based on the creation of delay lines by digital means. This way we emphasize that there is not a single way to implement these processes, even digitally or using individual delay lines without feedback. The implementation with delay lines, in a digital environment, helped didactically the understanding of how are produced and how we perceive the effects based on time delays and how it uses less resources of digital processing. We can also highlight that many time processes, analogical or digital, like racks, effect pedals and audio plugins may use more than one of these time processes in series or in parallel. It is possible also that we set, in a single processing unity, different processes like, for instance, chorus and reverb simultaneously. 


\section{References}

1. Berardino, Mauricio di. 2019. Muselectron: Tutorial su PureData, Max/MSP e Axoloti. Available at: https://muselectron.blogspot.com.br/p/pure-data.html Accessed in April of 2019.

2. Puckette, Miller S. 2006. The Theory and Technique of Electronic Music. World Scientific Publishing.

3. Réveillac, Jean-Michel. 2018. Musical Sound Effects: Analog and Digital Sound Processing. Iste Editions.

4. Roads, Curtis. 1996. The Computer Music Tutorial. The MIT Press. 